\title{
Study on Tertiary Infilling Adjustment Optimized Well Spacing at Super High Water Cut Stage
}

\author{
Li Lin
}

The Third Oil Production Factory, Daqing Oil Field Company Ltd, Daqing, Heilongjiang Province ,163000.

\begin{abstract}
In view of the features of the remaining oil after a period of production since secondary infilling adjustment of water flooding development oil field, that is, low quality, uneven planar distribution and high vertical dispersal, study on tertiary infilling adjustment optimized well spacing has been carried out in the East of North 3 Block of North Sartu Development Area. The study has solved the problems of reasonable well spacing density, injector-producer distance, injection-production system, how to locate wells near old injector array, and how to adjust and integrate with the original well pattern, with the tertiary recovery well pattern and with the injection-production system. The overall strategy and optimized well spacing method for tertiary infilling adjustment have been brought forward consisting of reasonable well location region division $\rightarrow$ balanced well spacing $\rightarrow$ well by well scanning $\rightarrow$ local adjustment $\rightarrow$ step by step implementation. The study has a wide guidance for the tertiary infilling adjustment of other blocks to find practical, feasible and effective approaches.
\end{abstract}

\section{East of North 3 Block Development Overview}

East of North 3 Block in North Sartu Development Area is located in the north pure oil area of Sartu Oilfield in Daqing placanticline with an oil bearing area of $20.2 \mathrm{~km} 2$. The block was brought into development in 1965 as major reservoirs in Sartu and Putaohua oil-field ${ }^{[1]}$. Since then two times of infilling adjustment had been conducted aiming at P II, Gao Middle, low permeability layers and Sartu thin and poor reservoirs. $250 \times 300 \mathrm{~m}$ inverted nine spots area injection pattern is adopted without exception. After secondary infilling, the well spacing density reached 30.25 wells/ $\mathrm{km}^{2}$.

According to the refined geologic anatomy result, the remaining adjustable sandstone thickness after secondary infilling adjustment in East of North 3 Block is predicted as $12.44 \mathrm{~m}$ and the effective thickness is $1.88 \mathrm{~m}^{[1]}$. Tertiary infilling adjustment has certainly material base, but uneven the remaining oil planar distribution and vertical high resolution have determined to the hardness of production potential development. Therefore, the approach should be started from technical and economical indexes to optimize well spacing with a possible better adjustment effect.

\section{Study on Tertiary Infilling Adjustment Optimized Well Spacing in East of North 3 Block}

\subsection{Tertiary infilling adjustment adopts five-spot area water flooding pattern, with well spacing of 200-250m and reasonable well spacing density lower than $\mathbf{5 0}$ wells $\mathbf{~ k m}^{2}$}

\subsubsection{Injection-Production System Screening}

Numerical simulation is applied to compare the development effects of five-spot pattern, four-spot pattern, and inverted nine spots injection-production systems in the thin and poor oil layers and surface layers in East of North 3 Block. The result shows that the average control degree of water flooding of five-spot area well pattern is 8-10\% high than other well patterns. At the same water cut, the recovery degree is higher than other injectionproduction systems. Therefore, the injection-production system of tertiary infilling adjustment in East of North 3 Block should select five spots pattern ${ }^{[2-5]}$.

\subsubsection{Reasonable Well Spacing Determination}

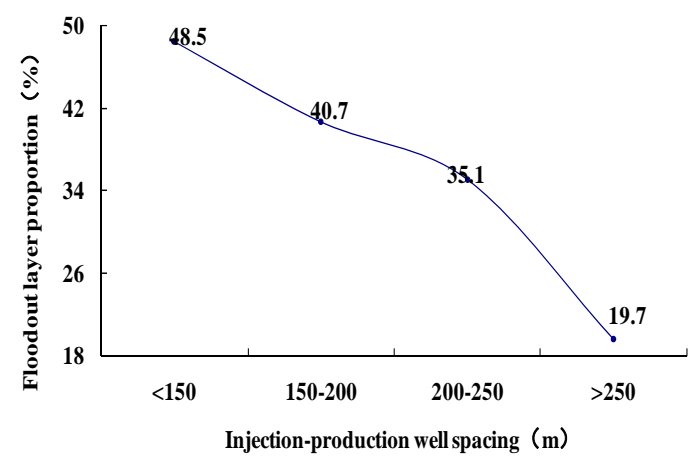

Figure 1. Surface reservoir floodout status at different injection-production well spacing

The test well data statistics show that the floodout proportion of surface reservoir gradually decreases with the increase of the distance between inspection well and water injection well. The distance limit of significant floodout status variance is $250 \mathrm{~m}$. When the injectionproduction well spacing is larger than $250 \mathrm{~m}$, the floodout proportion is only about $20 \%$. That means the thin and poor oil layers have a poor production if the well spacing is too large. On the other hand, the development study on the surface reservoirs of other blocks in the recent years also indicates that too small injection-production well spacing can cause unfavourable rapid water cut increase. Considering the factors of the above two aspects, the reasonable injection-production well spacing for thin and 
poor oil layer and surface layer effective development should be $200-250 \mathrm{~m}^{[2-5]}$.

\subsubsection{Reasonable Well Density Determination}

Numerical simulation is applied to compare the development effects of five-spot pattern, four-spot pattern, and inverted nine spots injection-production systems in the thin and poor oil layers and surface layers in East of North 3 Block. The result shows that the average control degree of water flooding of five-spot area well pattern is $8-10 \%$ high than other well patterns. At the same water cut, the recovery degree is higher than other injectionproduction systems. Therefore, the injection-production system of tertiary infilling adjustment in East of North 3 Block should select five spots pattern.

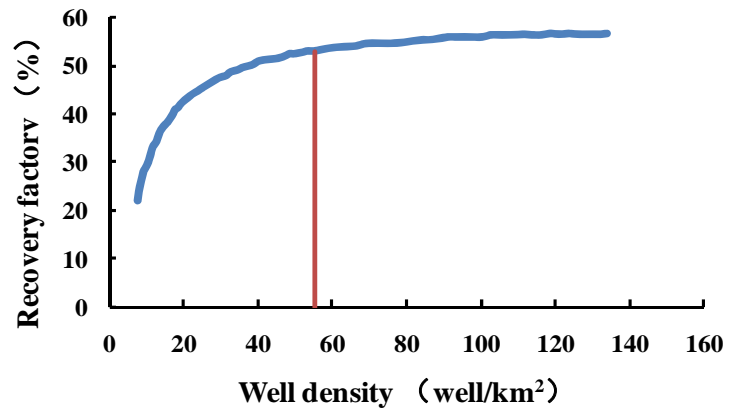

Figure 2. Recovery factory at different well density

The well density and water flooding recovery factor relation curve of East of North 3 Block indicates that the water flooding recovery factor increase is quite small when the well density is over 50 wells/ $\mathrm{km}^{2}$. This means that the reasonable well density of the tertiary infilling adjustment technology in East of North 3 Block should be controlled within 50 wells/ $\mathrm{km}^{2[6-7]}$.

\subsection{Tertiary infilling adjustment adopts the well spacing pattern of reasonable well spacing region division, balanced well spacing, well by well scanning, local adjustment}

\subsubsection{Reasonable well location region division according to the remaining oil research results with the economic benefit as the measure}

Considering the current crude oil price and the economic parameters during drilling, infrastructure construction and production, according to the principle of economic efficiency, the tertiary infilling well location regions are divided into:

Economic efficient region: single well estimated recoverable reserve is above 6,000t and converted effective thickness is larger or equal to $3.3 \mathrm{~m}$. The infilling wells located in this region can guarantee high production capacity and capital recovery capacity. Favourable economic benefit can be obtained while the development effect is improved. Therefore, drilling can be arranged first in this region.
Risk region: single well estimated recoverable reserve is 5,000-6,000t and converted effective thickness is $2.8-3.3 \mathrm{~m}$. The infilling wells located in this region have certain production capacity but the production is relatively lower. There is certain risk in technical and economic aspects. Rolling development technology can be adopted to implement drilling.

Reserved well region: single well estimated recoverable reserve is below 5,000t and the converted effective thickness is smaller than $2.8 \mathrm{~m}$. The experimental result in the dense well pattern in East of North 2 Block indicates that low efficient wells among those wells may occur with a large proportion. Under the current economic and technical conditions, it is not suitable to arrange adjustment at once. Well spacing can be done firstly in this region, while the infilling adjustment potential and well pattern integrated utilization should not be considered until economic and technical means are proper.

Once the well location region is determined, according to the five spots area injection-production system, with the well spacing of $200-250 \mathrm{~m}$, we dispose well sites evenly in different regions, among which the economically effective region area is $9.4 \mathrm{~km} 2$ with 144 wells, risk region area $4.3 \mathrm{~km} 2$ with 65 wells, and reserved well region area $6.5 \mathrm{~km} 2$ with 98 wells.

2.2.2 Local adjustment of tertiary infilling well sites according to well point remaining well distribution status

According to the research result on the well point remaining oil distribution status of the well location region, well by well scanning and local adjustment of tertiary infilling well sites are conducted in the first drilling well region. The first basic principle of well site adjustment is to avoid well location on the main stream line and the same well field; the second principle is to grasp the well site remaining oil rich layer intervals and coordinate the injection-production relation with wells of the adjacent strata series according to the adjustable thickness distribution features of the located well field; the third principle is to locate wells more than $150 \mathrm{~m}$ away from the scattered water flooding wells and to locate wells at remaining oil rich part; the fourth principle is to re-learn the faults and to locate wells more than $100 \mathrm{~m}$ away from fault lines which have a big influence on tertiary infilling wells according to the fault trend, dip angle and fault displacement and main located wells should be production wells.

\subsection{Flexible well spacing near the original injection well array, with appropriate enlargement of array and well spacing, as near as possible to the remaining oil rich part}

\subsubsection{No well location within $150 \mathrm{~m}$ around the original injection well array}

According to the accumulative water injection volume of the old injection wells, the distance between new well 
and old injection well, and the inter-new well water cut relation, the following mathematical model is established:

$$
d=1.9298 \quad 10-3 Q /(f w-42.178)
$$

in which $\mathrm{d}$-distance, $\mathrm{m}$;

$\mathrm{Q}$-cumulative water injection, $\mathrm{m}^{3}$;

$f_{\mathrm{w}}$-water cut, $\%$

The calculation indicates that the average cumulative water injection of the old injection wells in East of North 3 Block is about $200 \times 104 \mathrm{~m} 3$. If the water cut of tertiary infilling wells is desired to be controlled within $60 \%$, the distance between tertiary infilling of production well and old injection well should be larger than $150 \mathrm{~m}$.

After the new wells are brought into production in the tertiary infilling experimental region in East of North 3 Block, the comprehensive analysis on the floodout status of different injection well array distances also indicates that the unflooded proportion gradually increases and the floodout degrees vary a lot from $100 \mathrm{~m}$ to $300 \mathrm{~m}$. Within $100 \mathrm{~m}$ around the old water wells, the unflooded thickness proportion is only $7.5 \%$ and increases to $9.5 \%$ at $155 \mathrm{~m}$. The nearer to the injection well, the more severe is the floodout, and less is the remaining oil.

In view of the above analysis, no well is located on the original injection well array and within $150 \mathrm{~m}$ around the array in the East of North 3 Block.

\subsubsection{Flexible well location near the original injection wells according to different well array features}

North 3-3 array, North 2-1 array and North 2-3 array are the three old injection well arrays in East of North 3 Block. According to different well array production features, flexible well location methods are adopted such as deferred or evacuated well location.

(1) Low remaining oil potential. Well site design first, without drilling for the moment

North 3-3 array is the injection well array for the basic, first and secondary infilling wells. The well array has perforated all adjustable layers in Sartu, Putaohua and Gaotaizi oilfields, so the remaining potential is low. To guarantee the tertiary infilling adjustment effect, well sites are designed from North 3-1 to North 3-3 arrays, but with no drilling for the moment. The well locations may be considered at the later stage strata series well pattern integrated utilization.

(2) Deferred wells are located at drilling risk well arrays, adopting rolling development technology for drilling

North 2-1 array is the injection-production well array in Sartu and Putaohua main layers in the basic well pattern, at the same time is the injection well array for first and secondary infilling adjustment. The adjustable thickness distribution graph indicates it has further infilling adjustment potential. 25 tertiary infilling wells are disposed near this well array according to the range of adjustable thickness. Among them 13 wells are deferred drilling wells. In order to probe the remaining oil poor region for drilling feasibility, we select 3 proper deferred drilling wells and first implement drilling adopting rolling development technology. The other 10 deferred wells will be decided according to the drilling completion status of those 3 wells and the well arrays around North 2-1 array.

(3) North 2-3 array is mainly located by production wells, fully utilizing the secondary infilling injection well for water injection

North 2-3 array is also the injection-production well array in Sartu and Putaohua main layers in the basic well pattern. But since no well is located during the first infilling adjustment in the low permeable layers in this array, the secondary infilling injection wells are located between North 2-Ding 3 array and North 2-3 array, 120m away from North 2-3 array. The well spacing is quite large as $400-500 \mathrm{~m}$. The production target is the super low permeable thin and poor oil layer in Sartu oil layer. The production time is short and the floodout degree is relatively low. Therefore, the adjustable thickness is relatively large. This array adopts evacuated and well spacing enlargement methods. Main wells located between the secondary infilling injection wells are mainly production wells and water injection is mainly realized by the secondary infilling injection wells. At parts where injection-production system has defects, injection wells are supplemented as needed.

\subsection{Considering "three combinations" and implementing step by step to enhance comprehensive utilization rate of well pattern}

\subsubsection{Considering combination with original infilling well}

In order to analyze and evaluate the influence of the relationships between tertiary infilling well and original well pattern on development,we studied three series of well pattern including combination with the first and second infilling well patterns,with the second infilling well pattern,with the first infilling well pattern. When the procedure of tertiary infilling well pattern was arranged in East of North 3 Block, the results indicate that the first infilling adjustment well with moderate/low permeability layer located in P II and Gaotaizi reservoir in East of North 3 Block, thus P II and Gaotaizi reservoir ware not perforated when second infilling adjustment well was developed, but thin/poor oil reservoir is perforated. Based on producing status of P II and Gaotaizi reservoir is worse than Sartu reservoir, control degree of water flooding is relatively low, increasing significantly recoverable reserves by infilling well, allowing for using first infilling well pattern to discover fully remaining oil potentiality. On the other hand, well pattern using polymer flooding in Pu1 oil layer Formation adopts fivespot area pattern which is same used by tertiary infilling well, with well alignment spacing of $250 \times(200-250) \mathrm{m}$. All the oil/water wells are produced in Putaohua layer system by basic well pattern, infilling well between wells located in a series of basic well alignments and adding some arrays between arrays, corresponding to first infilling well interwell location or identical well site. At present, polymer flooding is used in Sartu oil layer at first, 
after F I Formation finished polymer flooding, then based on the requirements of development and technology level, returning to P II and Gaotaizi oil layer. Form a series of well pattern arrangements, as the polymer flooding well pattern upward Sartu oil layer, generating a little contradiction with the first infilling well produced moderate/low permeability in P II and Gaotaizi reservoirs, and the second infilling well used to produce thin/bad oil layer located in Sartu .Generally, returning upward Sartu oil layer is available, and workload of plugged mature well is small.

Polymer flooding is applied to produce P II + GaoI1-9 oil layer, which is the recoverable target for first infilling well in East of North 3 Block 。 The quantity of wells whose distance between polymer flooding well and first infilling well is less than $100 \mathrm{~m}$,are over $80 \%$ proportion in total wells, thus if recent polymer flooding well pattern is used to produce, first infilling well will almost stop production and injection .Obviously, the set of pattern for polymer flooding in P I Formation is not available. In the case, tertiary infilling adjustment is considered to associate with first infill well pattern. Tertiary infilling adjustment is used to develop polymer flooding in P II, Gaotaizi oil layer, when water cut of tertiary infilling well is up to economic level ${ }^{[8]}$.

Thus, based on the principle including enough digging remain oil potentiality and polymer flooding well pattern comprehensive utilization, tertiary infilling adjustment mainly refers to connect with first infill well pattern, such as recoverable type between well arrays, wells, placing of wells, injection sites, forming five-spot area well pattern. Well spacing of tertiary infilling injector producer is $250 \mathrm{~m}$. The distance from first infilling well is $175 \mathrm{~m}$.

\subsubsection{Proposal for associating with tertiary recovery}

Based on the above analysis, tertiary infilling adjustment associated with first infill well pattern, after water cut of tertiary infilling well is up to economic level, the set of tertiary infilling used to polymer flooding in $\mathrm{P}$ II , Gaotaizi oil layer by considering well pattern combination is available. Preliminary idea is, using recent tertiary recoverable well pattern and tertiary infilling well in economic available area to implement tertiary infilling and tertiary recovery by itself. In order to reduce plugging workload and difficulty when tertiary infilling is transformed to tertiary recovery, thin and bad oil layer and outside surface with low permeability by tertiary infilling is perforated but better not to perforate thick oil layer. As cut water of tertiary infilling well up to economic level, based on development condition, well site is adjusted in order to perforate oil layer with low permeability by decaying to drill tertiary infilling well and drilling tertiary infilling well on time and develop polymer flooding.

P II and Gaotaizi oil layer in East of North 3 Block is major inter-fore-facie deposition. Channel sand located in sub-sea diversion of deposit sand body is characterized by clearly banding. Channel sand develops narrow and low drilling ratio, and connectivity of oil layer is worse.
Polymer flooding tests developed for II Class reservoir indicate that, water flooding control degree of oil layer is low with well spacing of $250 \mathrm{~m}$. If thin and poor reservoir is associated, inter-bed interfaces are serious, and producing degree of thin and bad reservoir is low. Thus, there are two key problems about "two, three combination": well spacing; tertiary infilling and tertiary production adjustment target is controlled well. Thin and bad oil layer with effective thickness less than $1.0 \mathrm{~m}$ is acted as adjustment target to reduce the loss of available reserve. The target for polymer flooding is dominated by channel sand and lump sand distributed in local part. According to the characteristics of this type of reservoir, interval converted injection of first infilling well is used to reduce well spacing and form flooding pattern of the shape of oblique line with well spacing of less than $150 \mathrm{~m}$, then developing polymer flooding. Thus drilling well is implemented step by step, associating with comprehensive utilization of tertiary infill well pattern. It achieves requirements to produce upper and lower layer system, enhance availability of well pattern and reduce well spacing. The polymer flooding requirements of II Class is achieved and economic benefit is enhanced.

\subsubsection{Searching for potentiality of remaining oil in Sartu reservoir associated with adjustment of injection and production system}

From well site arrangement of various layer system and perforation, if Sartu, Putaohua and Gaotaizi reservoirs are all perforated by tertiary infilling adjustment in East of North 3 Block, following by several problems, see below:

(1) If the well spacing between tertiary infilling well and second infilling well for thin and bad reservoir located in Sartu is close, the difficulty of perforation will be increased widely.

Second infilling well in East of North 3 Block is located in interwell of first infilling well. The relationship of tertiary infilling adjustment with first infill well pattern is considered. Tertiary infilling adjustment with second infilling well used to produce thin and bad layer in Sartu area has a big contradiction. 144 tertiary infilling wells are in economic effective area based on statistics, and 125 wells are within $150 \mathrm{~m}$ from second infilling wells, with proportion of $86.8 \%$ in statistic wells. 60 wells (well spacing of injection and production is less than $80 \mathrm{~m}$ ) are in identical wells with the proportion of $41.7 \%$. Tertiary infilling well is developed based on second infilling well, so its production objective is similar with second infilling objective. The proportion for connectivity thickness is large. In that case, if tertiary infilling well is used to produce Sartu reservoir in East of North 3 Block, with close well spacing from second infilling well also used to Sartu reservoir, well interferences will be intensive and adjustment effect on tertiary infilling will be influenced.

(2) Water flooding control with high degree in Sartu reservoir, having a small contribution for enhancing available reserves after infilling

Based on the principle for oilfield development and infiltrating fluid, if water flooding control is up to certain degree, infilling adjustment well will only play a role for 
improving production, with a small proportion of increasing available reserves. However, water flooding control degree in Sartu reservoir in East of North 3 Block is up to $92.7 \%$, surface inside thin/bad and outside oil layers are to $93 \%$, however, water control degree of first infilling used in P II, Gaotaizi reservoirs is only up to contribution for enhancing recovery factor. However, P II, Gaotaizi reservoirs are main by enhancing available reserves contribution for enhancing recovery factor.

Table 1. Water flood control degree statistical table of primary and secondary infilling wells in East of North 3 Block

\begin{tabular}{|c|c|c|c|c|c|c|c|c|c|c|c|c|c|c|c|c|}
\hline \multirow{3}{*}{$\begin{array}{l}\text { Strata } \\
\text { series }\end{array}$} & \multirow{3}{*}{$\begin{array}{c}\text { Horizo } \\
\mathrm{n}\end{array}$} & \multicolumn{5}{|c|}{$\begin{array}{l}\text { Single, double direction connection } \\
\text { proportion }\end{array}$} & \multicolumn{5}{|c|}{$\begin{array}{c}\text { Connection proportion of above } 3 \\
\text { directions }\end{array}$} & \multicolumn{5}{|c|}{ Total connection proportion } \\
\hline & & \multicolumn{3}{|c|}{ Surface inside } & \multirow{2}{*}{$\begin{array}{l}\text { Surfa } \\
\text { ce } \\
\text { outsid } \\
\text { e }\end{array}$} & \multirow[b]{2}{*}{$\begin{array}{l}\text { Tot } \\
\text { al }\end{array}$} & \multicolumn{3}{|c|}{ Surface inside } & \multirow{2}{*}{$\begin{array}{c}\text { Surfa } \\
\text { ce } \\
\text { outsid } \\
\text { e }\end{array}$} & \multirow[b]{2}{*}{$\begin{array}{c}\text { Tot } \\
\text { al }\end{array}$} & \multicolumn{3}{|c|}{ Surface inside } & \multirow{2}{*}{$\begin{array}{c}\text { Surfa } \\
\text { ce } \\
\text { outsid } \\
\text { e }\end{array}$} & \multirow[b]{2}{*}{$\begin{array}{c}\text { Tot } \\
\text { al }\end{array}$} \\
\hline & & $\begin{array}{c}\text { Effecti } \\
\text { ve } \geqslant \\
0.5 \mathrm{~m}\end{array}$ & $\begin{array}{c}\text { Effecti } \\
\text { ve }< \\
0.5 \mathrm{~m}\end{array}$ & $\begin{array}{c}\text { Tot } \\
\text { al }\end{array}$ & & & $\begin{array}{c}\text { Effecti } \\
\text { ve } \geqslant \\
0.5 \mathrm{~m}\end{array}$ & $\begin{array}{c}\text { Effecti } \\
\text { ve }< \\
0.5 \mathrm{~m}\end{array}$ & $\begin{array}{c}\text { Tot } \\
\text { al }\end{array}$ & & & $\begin{array}{c}\text { Effecti } \\
\text { ve } \geqslant \\
0.5 \mathrm{~m}\end{array}$ & $\begin{array}{c}\text { Effecti } \\
\text { ve }< \\
0.5 \mathrm{~m}\end{array}$ & $\begin{array}{c}\text { Tot } \\
\text { al }\end{array}$ & & \\
\hline $\begin{array}{l}\text { Primary } \\
\text { infilling }\end{array}$ & $\begin{array}{l}\text { P II } \\
\text { Gao }\end{array}$ & 59.9 & 60.7 & $\begin{array}{c}60 . \\
5\end{array}$ & 63.1 & $\begin{array}{c}62 . \\
9\end{array}$ & 26.6 & 16.4 & $\begin{array}{c}21 . \\
8\end{array}$ & 16.0 & $\begin{array}{c}18 . \\
6\end{array}$ & 86.5 & 77.1 & $\begin{array}{c}82 . \\
3\end{array}$ & 79.1 & $\begin{array}{c}81 . \\
5\end{array}$ \\
\hline $\begin{array}{l}\text { Seconda } \\
\text { ry } \\
\text { infilling }\end{array}$ & Sartu & 63.8 & 63.5 & $\begin{array}{c}63 . \\
7\end{array}$ & 63.0 & $\begin{array}{c}63 . \\
5\end{array}$ & 27.3 & 29.9 & $\begin{array}{c}28 . \\
2\end{array}$ & 30.1 & $\begin{array}{c}29 . \\
2\end{array}$ & 91.1 & 93.4 & $\begin{array}{c}91 . \\
9\end{array}$ & 93.1 & $\begin{array}{c}92 . \\
7\end{array}$ \\
\hline
\end{tabular}

(3) A small potentiality of remaining oil in Sartu reservoir, with a big difficulty for digging

Producing status of various reservoirs in Sartu reservoir after second infilling was very high, so available adjustment thickness is relative small. In available adjustment thickness Formation, available adjustment thickness in Sa II, Sa III reservoir Formation has over $80 \%$ proportion in overall Sartu reservoirs, dominated by a big proportion. From the results of producing layer system by polymer flooding, several produced layers with part adjustment objective in Sa 二, 三 reservoir Formation adopted by tertiary infilling well results in a contradiction. Thus, if polymer flooding well is not used to produce reservoir but diminishing a part of available adjustment layer, the adjustment thickness in Sartu reservoir will become smaller and smaller.

In addition, based on study results of infill well pattern in test area, the distribution of this type of reservoir with water flooded zone is interactive. Although early productivity requirements are assured, containing water increases quickly. From the production results of 7 commingled producing wells including Sartu, Putaohua, Gaotaiz areas, perforated thickness in Sartu reservoir, relative liquid production has a proportion of, respectively, $30.4 \%, 43.2 \%$ in total overall well, and containing water is up to $74.1 \%$, is respectively $14.5 \%$, 22.4\% higher than Putaohua, Gaotaizi reservoir.

In order to reduce contradictions between inter-bed and inter-well and control water cut increasing ratio, producing status of various reservoirs are enough improved. Pu2 Formation and lower oil layer is perforated at first as tertiary infilling adjustment in East of North 3 Block. Sartu reservoir mainly associated with injection and production system adjustment is produced. Two preliminary ideas: For tertiary infilling well having a small contradiction with second infilling, based on detail analysis of various remaining oil source, Sartu, Putaohua and Gaotaizi reservoirs are all together perforated; For tertiary infilling well having a big contradiction with second infilling, Pu2, Gaotaizi part reservoirs and oil/water identical interval with relative higher oil saturation is completed firstly. When the proper adjustment time on injection and production system of second infilling well is mature, available adjustment layer in Sartu reservoir is perforated. The injection and production well spacing is reduced by converting oil well to produce.

Table 2. Primary various oil layers production table for commingled producing well of Sartu, Putaohua, Gaotaizi areas in dense infilling well pattern test area

\begin{tabular}{|c|c|c|c|c|c|c|}
\hline Oil layer & Classification & Sandstone & Effective & $\begin{array}{c}\text { Liquid } \\
\text { production }\end{array}$ & $\begin{array}{c}\text { Oil } \\
\text { production }\end{array}$ & $\begin{array}{c}\text { Water } \\
\text { cut }\end{array}$ \\
\hline \multirow{2}{*}{ Sartu } & Numerical value & 7.33 & 1.84 & 10.03 & 2.60 & \multirow{2}{*}{74.08} \\
\hline & Proportion to the whole block (\%) & 30.41 & 43.91 & 43.21 & 31.33 & \\
\hline \multirow{2}{*}{ Putaohua } & Numerical value & 4.17 & 0.78 & 8.51 & 3.44 & \multirow{2}{*}{59.56} \\
\hline & Proportion to the whole block (\%) & 17.30 & 18.62 & 36.67 & 41.47 & \\
\hline \multirow{2}{*}{ Gaotaizi } & Numerical value & 12.6 & 1.57 & 4.67 & 2.26 & \multirow{2}{*}{51.68} \\
\hline & Proportion to the whole block (\%) & 52.28 & 37.47 & 20.12 & 27.19 & \\
\hline Total & Numerical value & 24.10 & 4.19 & 23.21 & 8.30 & 64.25 \\
\hline
\end{tabular}


Based on adjustment ideas and study results, 307 tertiary infilling wells are in East of North 3 Block (including 182 oil wells, 125 water wells), well spacing density is 45.5 wells/km2.Of the 307 tertiary infilling wells, 144 are located in economic effective area (including 13 delayed wells, 131 first drilled wells).

\section{Conclusions}

(1) A certain amount of remaining oil is still present in East of North 3 Block by second infilling well. Adjustment of sandstone thickness is $12.44 \mathrm{~m}$ by prediction, the relative thickness is $1.88 \mathrm{~m}$ with outside reservoir of $6.93 \mathrm{~m}$. These are all material basis for tertiary infilling adjustment.

(2) Tertiary infilling adjustment well pattern is based on detailed geologic research and the study results of remaining oil. Several procedures are implemented, such as reasonably dividing placing of wells areas, uniform placing of wells, scanning wells and local adjustment, to determine all the placing spots dropping remaining oil rich parts.

(3) New and old wells should be considered as implementing tertiary infilling and improve the relationship between injection and production. Reasonable well spacing density is $50-60$ wells $/ \mathrm{km}^{2}$, and well spacing of injection and production is $200-250 \mathrm{~m}$. None but having certain injection water sites, better development effect can be achieved.

(4) If well alignment for oil injection water well within $150 \mathrm{~m}$ is not need to placing, but if over $150 \mathrm{~m}$, it can be based on distribution condition about remaining oil to use several placing of well method including temporary slow and lax placing of wells.

(5) Tertiary infilling placing of wells is proposed considering "three combinations", implementing step by step to improve comprehensive utilization of well pattern and economic benefits.

\section{References}

[1] Yusun Jin. Production Geologic Engineering [M] .Beijing:Petroleum Industry Press,1985.

[2] Chuanzhi Cui, Chichen Yang, Shuanwen Niu et al. Determination of reasonable well spacing and influencing factors for the complicated fault-block reservoirs at high water cut stage. PGRE, 2013, 20 (4):53-56.

[3] Jing Wen. Well pattern and spacing optimization for surfactant/polymer flooding in high water cut reservoirs of Liaohe oilfield.[J]. Special Oil and Gas Reserviors,2012,19(2):73-75.

[4] Xiansong Zhang, Xiaoqing Xie, Minfeng Chen. Study on rational well pattern and well spacing in low permeability gas field[J]. Petroleum Geology and Recovery Efficiency, 2011,18(6):94-96.

[5] Xiaoping Kang, Jun Tang. Determination of rational well spacing in low permeability sandstone reservoir by dynamic analysis[J]. Special Oil and Gas Reserviors, 2006,1(6):64-66.
[6] Lei Yang, Jun Cheng, Qi Wang. Improved Method for Calculating the Economy Rational Well Spacing Density in Matured Oilfield [J]. Inner Mongolia Petrochemical Industry, 2007,33(5):122-123.

[7] Xiancheng Wu. A Method of Selection of Optimum Well Spacing[J]. ACTA PETROLEI SINICA, 1985,6(3):113-120.

[8] Jian Li. A Study of Residual Oil Distribution of Main Reservoir Group of Daqing Oil Field after Polymer Flooding[D]. Daqing : Northeast Petroleum University, 2003:53-64. 